Paper

\title{
Temporal Aspects of Lighting: A Study on Detection and Acceptance during Starting
}

\author{
John D. BULLOUGH, Ramesh RAGHAVAN, Richard M. PYSAR and Yukio AKASHI
}

Lighting Research Center, Rensselaer Polytechnic Institute, 21 Union Street, Troy, NY 12180 USA

Received April 10, 2006, Accepted October 20, 2006

\begin{abstract}
Temporal characteristics of fluorescent lighting systems during starting might affect their acceptance in commercial and residential lighting. The immediate, full onset of light is usually experienced when switching on incandescent lamp systems. For certain systems using fluorescent lamps, delayed onset or initially low light levels might be experienced. Such characteristics could make them unwelcome additions to commercial and residential settings. The results of a study to investigate subjective and behavioral responses to lighting systems having different temporal characteristics upon start-up are presented.
\end{abstract}

\section{KEYWORDS: illuminance, start-up, warm-up, acceptability}

\section{Background}

The addition of amalgams to the mercury used in certain compact fluorescent lamps ${ }^{12)}$ reduces the impact of lamp operating position (e.g., base up, base down or horizontal). However, amalgams tend to result in decreased initial light output that slowly rises over a warm-up time of a few minutes. Additionally, the use of ballasts other than instant-start types in some fluorescent lamp systems can result in noticeable delays upon switching on the lighting ${ }^{3)}$. These are important factors because the perception of poor performance of lighting technologies could result in decreased market acceptance ${ }^{4)-6)}$. For this reason, a study of perceptions under different temporal start-up conditions (delays and slow increases in light output upon switching) was performed.

The literature on temporal aspects of the luminous environment focuses largely on very fast fluctuations in light such as flicker ${ }^{7-9}$. Some work on noticeability of slower fluctuations has been conducted. For slow changes in light output (occurring over a period of several seconds to several minutes), the point at which individuals tend to notice these changes occurs when the light level is changed by about $\left.20 \%^{10}\right)^{-15}$, regardless of the rate of change (and excluding nearly-instantaneous changes). If individuals were aware that such changes increased energy efficiency, they were willing to accept noticeable changes in light level even larger than $30 \%$ to $40 \%{ }^{15}$.

In an evaluation of the perception of light level differences, side-by-side and sequential comparisons of light levels provided by incandescent lamps having standard (e.g., 60,75 or $100 \mathrm{~W}$ ) and reduced (e.g., 54, 67 or $90 \mathrm{~W}$ ) wattages were conducted (unpublished data). Reducedwattage incandescent lamps available in North America have correspondingly reduced lumen output ratings. In side-by-side comparisons, differences (between 75 and $67 \mathrm{~W}$, for example) were reliably detected. When subjects viewed the lighting conditions sequentially, separated by a period of several seconds, differences were only detected at chance $(50 \%)$ level. Such data indicate that small $(\sim 10 \%)$ differences in light output are notice able only when they appear simultaneously in the field of view, but not when separated by even short periods of time.

In all of the above-mentioned studies, subjects were aware of and were specifically looking for, changes or differences in light output. In an actual lighting installation, occupants would not expect such changes. This difference in expectation might have made the subjects in those studies more sensitive to changes in lighting conditions than occupants of an actual lighted space.

The impact on acceptance of delayed onset was not explored in previously published studies, particularly in conjunction with slowly changing light output such as might be experienced with amalgam-based fluorescent lamps. The present study was conducted to investigate the responses of individuals when the onset of lighting is delayed after switching on a light and when the onset of light to full output occurred over a period of several seconds. In particular, the present study used subjects who were unaware that such changes might be occurring. 


\section{Method}

The study was conducted in a small, windowless laboratory that was $3 \mathrm{~m}$ long by $3 \mathrm{~m}$ wide (wall and ceiling reflectance 0.9 , floor reflectance 0.3 ). Two $1 \mathrm{~m}$ deep by $2 \mathrm{~m}$ long work tables (table top reflectance 0.4) were located inside the room with a height of $1 \mathrm{~m}$. One of the work tables contained a computer and electrical measurement equipment, and the other table was mostly empty, and was used for the present study. A small table lamp luminaire fitted with a low-voltage (28V) halogen lamp was located $0.2 \mathrm{~m}$ from the wall in the center of this latter work table. The $28 \mathrm{~V}$ lamp was used because of the relative ease of which its light output can be changed with a direct current power supply being controlled through Labview software. The ceiling height along the wall adjacent to the table lamp was $3.6 \mathrm{~m}$ and the ceiling sloped slightly downward to a height of $3.2 \mathrm{~m}$ along the opposite
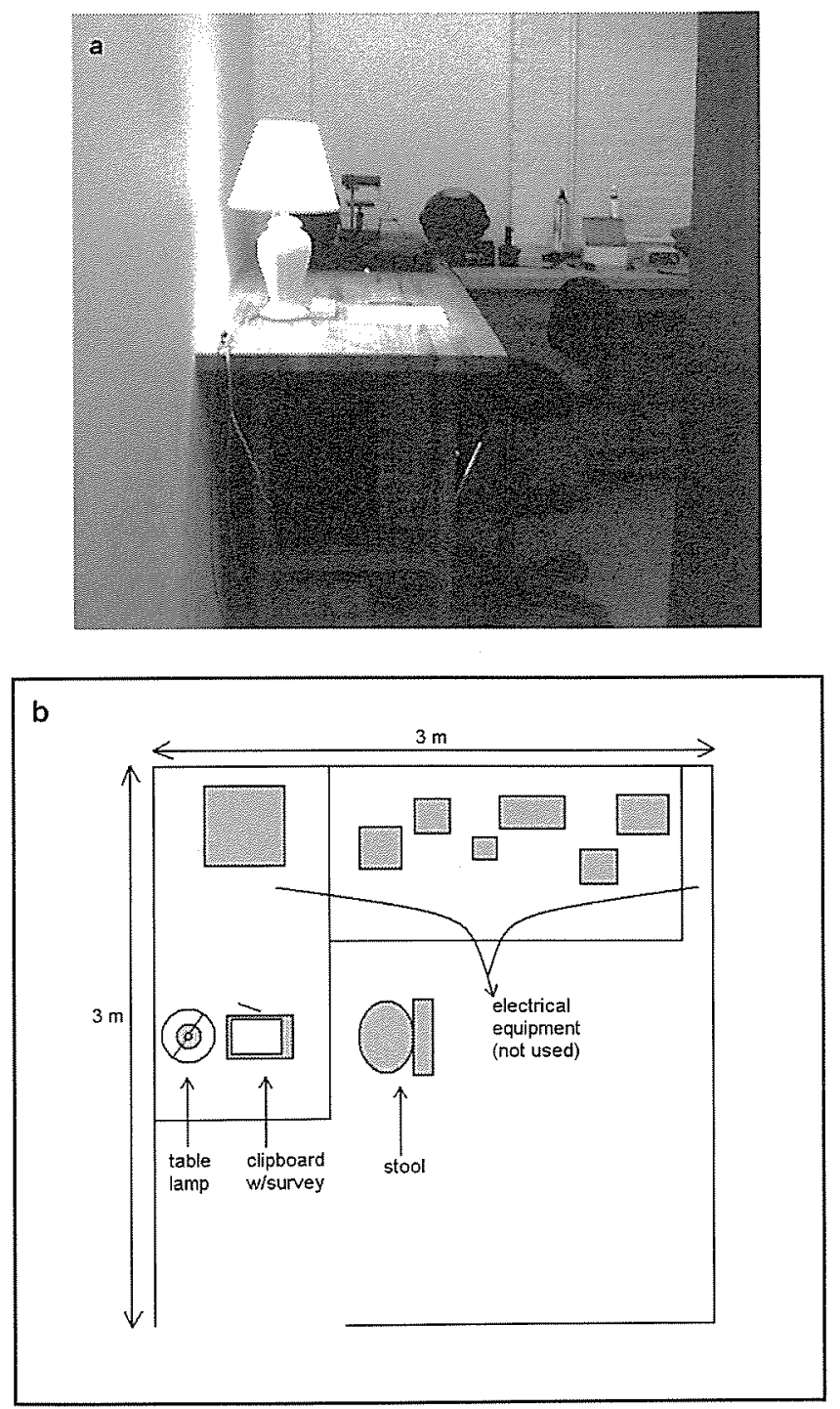

Figure 1 Experimental room showing table lamp (a: photograph, b: plan drawing) wall. A rocker switch located near the base of the luminaire was used to switch it on and off. A stool was located in front of the table containing the table lamp. Figure 1 shows a photograph and plan view of the experimental laboratory.

The door of the laboratory remained open and the space outside the door was dimly lighted so that there was a horizontal illuminance of $0.5 \mathrm{~lx}$ on the work area in front of the luminaire. When the table lamp luminaire was lighted to full light output, the horizontal illuminance on the work plane was $750 \mathrm{~lx}$, while the horizontal illuminance near the wall opposite the table lamp was $50 \mathrm{~lx}$. The vertical illuminance $15 \mathrm{~cm}$ above the table lamp on the adjacent wall was $650 \mathrm{~lx}$ and the vertical illuminance on the opposite wall was $25 \mathrm{~lx}$. A clipboard containing a copy of a survey questionnaire (printed on paper with reflectance of 0.7 ) and a pen was located in front of the luminaire.

Three onset profiles (control, delay and ramp-up) were used to control the light output from the luminaire. Figure 2 shows these three profiles. For the control condition, the lamp increased nearly immediately to $100 \%$ light output (the lamp itself had a warm up time of approximately $250 \mathrm{~ms}$ ). A delay condition was used whereby a $1.5 \mathrm{~s}$ delay occurred between pressing the switch and the full output of the lamp. Finally, a rampup condition was used, where switching on the luminaire resulted in the lamp increasing nearly immediately to $50 \%$ light output $(23 \mathrm{~V})$, and then slowly increased to $100 \%$ light output (28V) linearly over a $10^{-\mathrm{s}}$ period of time. At 50\% light output, the horizontal illuminance on the work plane was $375 \mathrm{~lx}$.

The selection of the $1.5^{-\mathrm{s}}$ delay characteristic was based in part to test the 1-s delay suggested by the U.S. ENERGY STAR ${ }^{\circledR}$ program $^{16)}$ as an acceptable limit for delays for compact fluorescent lamps. Since the $1.5 \mathrm{~s}$ delay in this study exceeded the ENERGY STAR ${ }^{\otimes}$ limit ${ }^{16)}$, it was expected that this would be found to be unacceptable. The $50 \%$ initial light output and 10-s

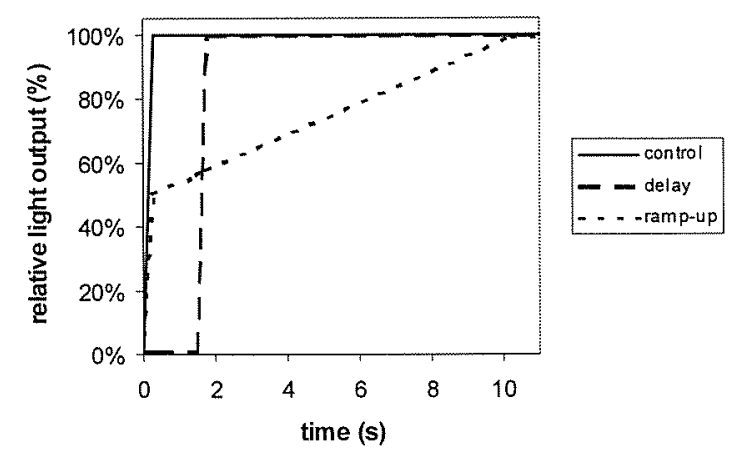

Figure 2 Onset profiles used in the study (100\% refers to $750 \mathrm{~lx}$ on the horizontal work plane) 
ramp-up time was selected to have conditions that would be expected to be readily apparent to an alerted observer 10)-15). This initial light output value was calculated ${ }^{17)}$ and subsequently determined to have only a small impact $(<200 \mathrm{~K})$ on the correlated color temperature (CCT) of the lamp when it was started in the dimmed condition. The measured CCT of the lamp was $2790 \mathrm{~K}$ at $100 \%$ output and $2600 \mathrm{~K}$ at $50 \%$ output. Observations by experimenters of the ramp-up condition in the experimental laboratory indicated that it was very difficult, if not impossible, to detect the color change when presented simultaneously with the light level change. Narendran et al ${ }^{18)}$. reported that CCT differences of 300 to $400 \mathrm{~K}$ were close to the detection threshold near $3000 \mathrm{~K}$ in visually complex environments. For these reasons, the shift in CCT as the halogen lamp increased from $50 \%$ to $100 \%$ output over the 10 -s ramp-up period was considered to be of secondary significance.

Thirty subjects ranging in age from 20 to 63 years participated in the study (18 females and 12 males). The experimental procedure was straightforward. Subjects were asked to enter the room, turn on the table lamp luminaire, and complete the survey. The door remained open at all times. Subjects were assigned in sequence to the control, delay or ramp-up condition and saw only that condition, so that ten subjects were assigned to each group.

After several demographic questions about gender, age, color vision and corrective lenses (Q1 through Q4 in Figure 3), the survey contained several "distractor" questions about how natural the color of the light was, and how appropriate the light level would be for an office space and for a storage closet (Q5 through Q7 in Figure 3). At the end of the questionnaire were several questions focusing on the onset of the luminaire, whether any changes in light level were detected once the luminaire switched on, and the acceptability of these aspects (Q8 through Q11 in Figure 3). It was expected that there would be no significant differences among the groups in terms of demographic characteristics or in terms of the subjective responses to the distractor questions, but that there might be differences among the groups in terms of their perceptions of the temporal characteristics of the lighting, since these were the only factors that differed among the groups.

An experimenter also observed each subject's behavior upon entering the room and switching on the luminaire, because the $1.5 \mathrm{~s}$ time period associated with the delay condition was long enough that it was believed some subjects might either report that the luminaire was not working properly or ask if this was so, or press the switch again, or try to see if they actually pressed the switch.

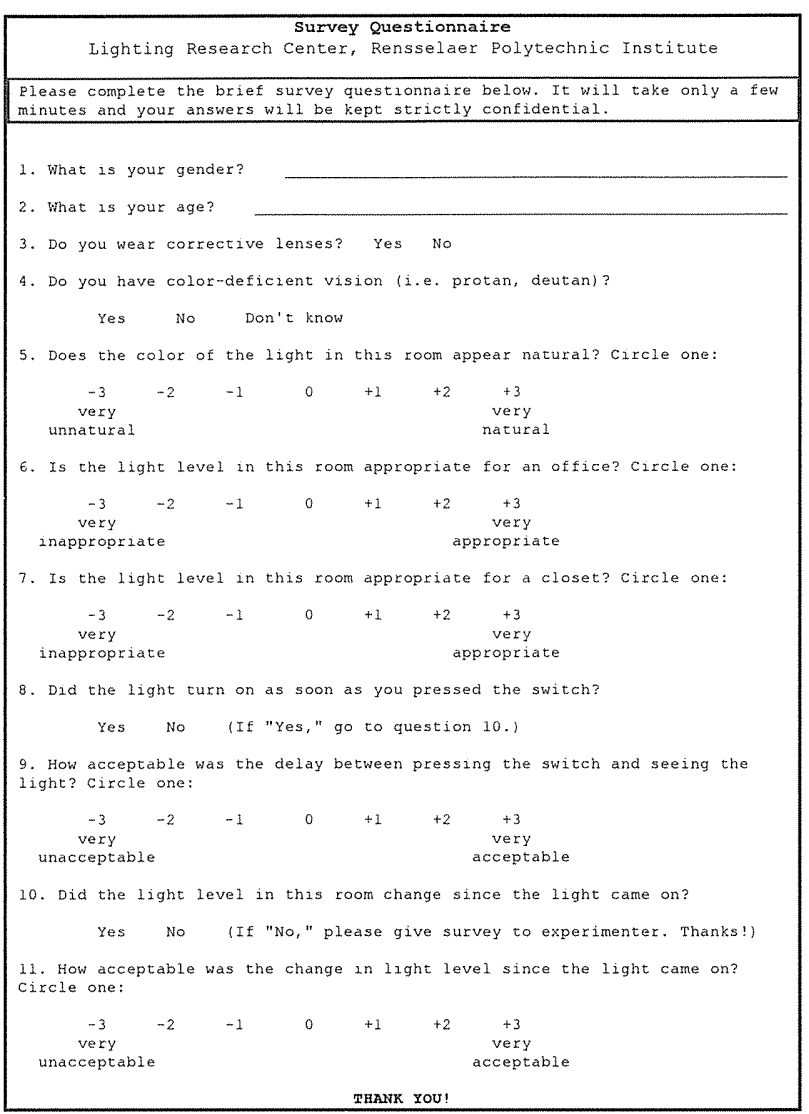

Figure 3 Questionnaire used in the study

\section{Results}

\subsection{Subject Demographics}

It was not expected that there would be significant differences among the demographic characteristics in each group, and among-groups, one-way analyses of variance (ANOVAs) on the responses to questions 1 through 4 about gender, age, corrective lenses and color vision bore out this expectation ( $p>0.4$ for all analyses, suggesting no significant differences among groups).

\subsection{Distractor Questions}

The distractor questions 5 through 7 pertained to the final light level and distribution in the room, which did not differ among the three conditions. Seven-point scales ranging from -3 to 3 were used in these questions. Among-groups, one-way ANOVAs on the responses to Q5 about the naturalness of the color appearance $(-3=$ very unnatural, $3=$ very natural), Q6 about the appropriateness of the light level for an office $(-3=$ very inappropriate, $3=$ very appropriate $)$ and $Q 7$ about the appropriateness of the light level for a storage closet (using the same scale as for Q6) found no statistically significant differences among the groups $(p>0.2$ for all analyses). 
Interestingly, the lighting condition (750 lx on the work plane and $50 \mathrm{~lx}$ at the opposite side of the room) was rated overall as slightly unacceptable (mean rating of -0.3 ) for an office, and as moderately acceptable (mean rating of 0.8 ) for a storage closet, perhaps indicating that the large degree of nonuniformity in illuminance throughout the room would be more acceptable in a closet than in an office. This difference was statistically significant $(p<0.01)$, according to a two-tailed, paired Student's t-test.

\subsection{Delay Questions}

Question 8 was a yes/no question asking whether the light turned on as soon as the switch was pressed. As shown in Figure 4, none of the subjects in the delay group (with a $1.5^{-\mathrm{s}}$ delay) reported that the luminaire turned on immediately. However, only about $30 \%$ of the subjects in both the control and ramp-up groups reported that the luminaire turned on right away. This is possibly because of the $\sim 250 \mathrm{~ms}$ onset time of the halogen lamp in the luminaire. While an among-groups, one-way ANOVA found no significant differences among the three groups' responses to Q8, there was a statistically significant difference $(p<0.05)$ between the control and delay groups using a one-tailed Student's t-test (assuming there would be fewer "yes" responses in the delay group).

Question 9 asked subjects to rate the acceptability of the delay (if they noticed a delay), using a seven-point scale $(-3=$ very unacceptable, $3=$ very acceptable). If subjects did not notice a delay, the response to this question was assumed to be 3 for the purpose of data analysis, and the responses are shown in Figure 5. An among-groups, one-way ANOVA found a significant difference among the groups in responses to this question $(p<0.001)$, and a one-tailed Student's t-test confirmed that, as hypothesized, the delay condition had significantly lower $(p<0.0001)$ acceptability ratings (mean rating of -1 ) than the control condition (mean rating of 2 ). Inspection of Figures 4 and 5 also indicates that while the control and ramp-up conditions were not observed to switch on immediately, these delays were judged to be acceptable (based on the mean acceptability ratings of 2 for these conditions).

\subsection{Ramp-Up Questions}

Question 10 asked subjects whether they detected the light level changing in the room once the light came on (Figure 6). While slightly more people in the ramp-up group (40\%) responded that they detected a change than in the other groups, there were enough similar responses in the control (20\%) and delay (30\%) groups that there were no significant differences using an among-groups, one-way ANOVA ( $p>0.6$ ). Thus, as might be expected, there were also no significant differences

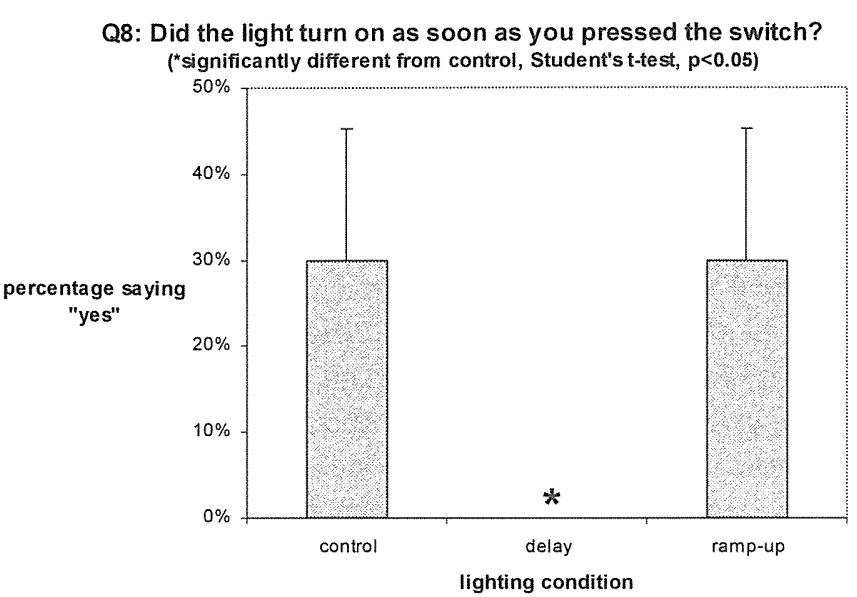

Figure 4 Responses to question 8

Q9: How acceptable was the delay? (*significantly different from control, Student's t-test, $p<0.0001$ )

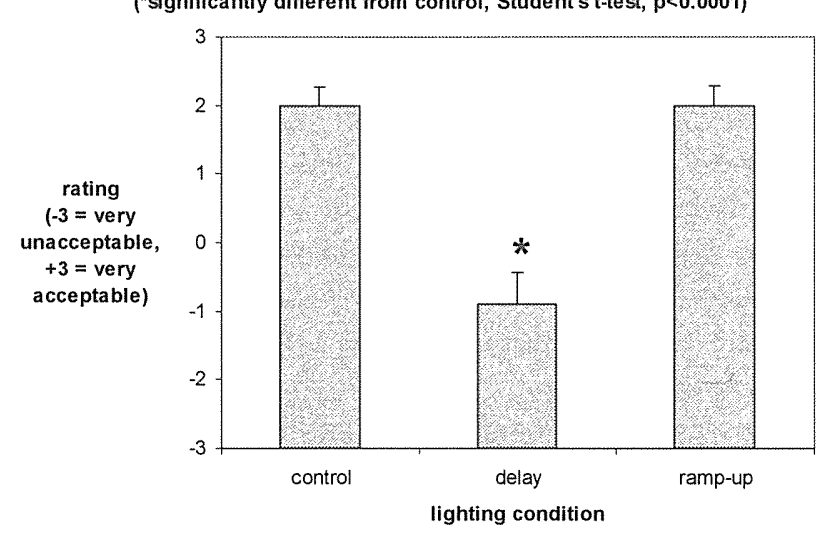

Figure 5 Responses to question 9

among the groups in terms of the responses to question 11 (Figure 7), which asked about the acceptability (using the same rating scale as for Q10) of the change in light level (assigning a response of 3 if no change was detected), using an among-groups, one-way ANOVA $(p>0.6)$. Indeed, the average ratings for all conditions for question 11 were very close to 3 , indicating that the ramp-up, even when it was detected, was found to be very acceptable.

\subsection{Behavioral Responses}

As described above, an experimenter observed the behavior and verbal responses of subjects upon pressing the switch to turn on the luminaire, recording if subjects complained or asked about the luminaire or made effort to switch on the luminaire again.

Under the control and ramp-up conditions, there were no such responses; under the delay condition, $40 \%$ of the subjects had some kind of behavioral response. These responses involved subjects asking whether there was a problem, attempting to switch the luminaire on 


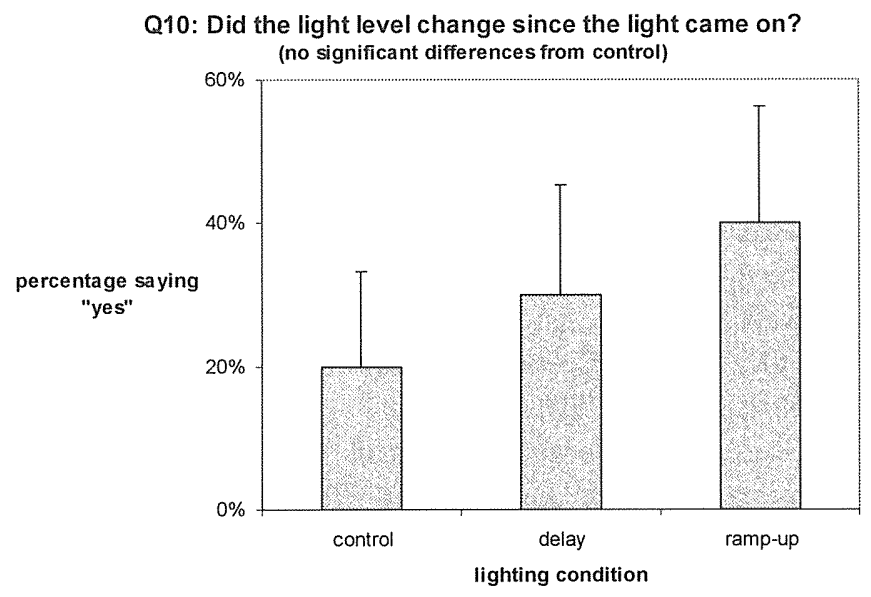

Figure 6 Responses to question 10

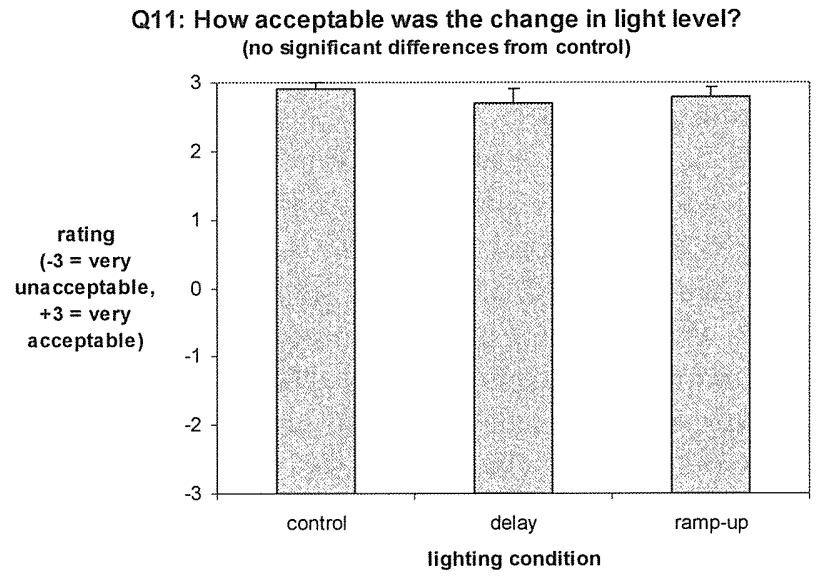

Figure 7 Responses to question 11

again (two responses), or looking underneath the luminaire for the lamp inside. Using an among-groups, oneway ANOVA there was a statistically significant $(p<0.05)$ difference among the conditions. Using the assumption that the delay condition would elicit more such behaviors, a one-tailed Student's t-test showed a significant $(\mathrm{p}<0.05)$ difference between the control and delay conditions.

\section{Discussion}

The 1.5 $\mathrm{s}$ interval between pressing the switch and the onset of the luminaire in the delay condition was clearly found to be unacceptable, while the much shorter delay associated with the warm-up of the halogen lamp used in this study $(\sim 250 \mathrm{~ms})$ seemed to be rated much more acceptable to people. Based on these limited data, the 1-s maximum delay after switching that has been proposed for compact fluorescent lamps ${ }^{16)}$ is probably reasonable in that longer delays (such as $1.5 \mathrm{~s}$ ) are rated as unacceptable.

As for the ramp-up characteristics, this effect was not noticed significantly more in the ramp-up group than in the other groups where the luminaire produced $100 \%$ of its light output the entire time it was on. The approximately $20 \%$ to $30 \%$ false positive rate in the control and delay conditions demonstrates the difficulty of making these judgments when observers are not specifically made aware that they should pay specific attention to these factors. While prior literature found that most subjects could reliably detect a $20 \%$ change in light level, the present study found that most $(60 \%)$ people did not detect a $100 \%$ change in light level in the ramp-up group.

While it has been previously found that increases in light level were slightly more difficult to detect than decreases ${ }^{12)}$, this factor does not seem to fully explain the inability of many subjects in the present study to detect the large difference in light level (an increase of $100 \%$ from 0 to $10 \mathrm{~s}$ ). This apparent contradiction is most likely explained by the methods used in the present study. As discussed above, other studies ${ }^{10)-1.5)}$ spe- $^{-}$ cifically asked subjects to focus on changes in light level and used within-subjects experimental designs (subjects were exposed to multiple changes in light level). In contrast, subjects in the present study were not prompted to pay attention to changes in light level, the distractor questions were designed to prevent subjects from thinking about such changes until after they would have occurred, and a between-subjects experimental design was used such that each subject experienced only one condition.

\section{Conclusions}

A minimum recommended initial light output of $50 \%$ seems to be a reasonable criterion in realistic situations, when observers' attention would not be drawn specifically to the possibility of temporal changes in light level. Thus, the use of amalgam lamps having long warm-up times might be quite acceptable for many lighting applications where lighting is switched on (in contrast to general ambient systems that are switched on and remain on during the day or continuously), provided they produce enough light output initially.

Future study should investigate different intervals between immediate onset and the 1.5-s delay used in the present study to more precisely pinpoint what the maximum delay that would be considered acceptable (or undetectable) by most people is. In addition, initial light output percentages lower than $50 \%$ should be explored as well to determine what the lower limit of this value is to make such changes inconspicuous.

\section{Acknowledgments}

This study was supported by the U.S. Environmental Protection Agency. Mark Rea, Mariana Figueiro and 
Jennifer Fullam from the Lighting Research Center are acknowledged for their helpful contributions to this study.

\section{References}

(1) Serres, A. W. and Taelman, W.: Amalgams and compact fluorescent lamps, IEEE Industrial Applications Conference, 28th IAS Annual Meeting, Piscataway, NJ, pp.2296-2304 (1993).

(2) Serres, A. W. and Taelman, W: A method to improve the performance of compact fluorescent lamps, J. Illum. Engng. Soc., Vol.22 No.2, pp.40-48 (1993).

(3) Narendran, N., Yin, T., O'Rourke, C., Bierman, A. and Maliyagoda, N.: A lamp life predictor for frequently switched instant-start fluorescent systems, J. Illum. Engng. Soc., Vol.30 No.2, pp.189-198 (2001).

(4) Kjoerulf, F.: Transforming the CFL market by consumer campaigns, Right Light 4 Conference Proceedings, Copenhagen, Denmark, pp.145-147 (1997).

(5) Figueiro, M. G., Fullam, J., O'Rourke, C., Overington, M., Rea, M. S. and Taylor, J.: Increasing Market Acceptance of Compact Fluorescent Lamps [report to U.S. Environmental Protection Agency], Troy, NY, Rensselaer Polytechnic Institute (2003).

Accessed on March 10, 2006 at http://www.Irc.rpi.edu/ programs/lightingtransformation/colorroundtable/pdf/ marketacceptanceofcflsfinal.pdf.

(6) Bullough, J. D.: Research matters: Is the warm-up worth it?, Light. Des. Appl., Vol.35 No.11, pp.10-12 (2005).

(7) Kelly, D. H.: Visual responses to time-dependent stimuli: I. Amplitude sensitivity measurements, J. Opt. Soc. Am., Vol.51, pp.422-429 (1961).

(8) Kelly, D. H.: Visual responses to time-dependent stimuli: II. Single-channel model of the photopic visual system, J. Opt. Soc. Am., Vol.51, pp.747-754
(1961).

(9) Watson, A. B.: Temporal sensitivity, In Handbook of Perception and Human Performance, Volume 1, New York, NY, Wiley and Sons (1986).

(10) Knau, H.: Thresholds for detecting slowly changing Ganzfeld luminances, J. Opt. Soc. Am. A, Vol.17 No.8, pp.1382-1387 (2000).

(11) Kryszczuk, K. and Boyce, P. R.: Detection of slow light level reduction, J. Illum. Engng. Soc., Vol.31 No.2, pp.3-10 (2002).

(12) Neches, J.: Detectability and Acceptability of Illuminance Reduction for Load Shedding (M.S. thesis), Troy, NY, Rensselaer Polytechnic Institute (2003).

(13) Shikakura, T., Morikawa, H. and Nakamura, Y: Perception of lighting fluctuation in office lighting environment, J. Light \& Vis. Env., Vol.27 No.2, pp.75-82 (2003).

(14) Akashi, Y. and Neches, J.: Detectability and accept ability of illuminance reduction for load shedding, $\mathrm{J}$. Illum. Engng. Soc., Vol.33 No.1, pp.3-13 (2004).

(15) Akashi, Y. and Neches, J.: Potential recommendations for illuminance reductions by load-shedding, Light. Res. Technol., Vol.37 No.2, pp.133-153 (2005).

(16) ENERGY STAR ${ }^{\circledR}$ : Compact Fluorescent Light Bulbs Key Product Criteria, Washington, D.C., U.S. Environmental Protection Agency (2003).

Accessed on March 10, 2006 at http://www.energystar. gov/index.cfm?c=cfls.pr_crit_cfls.

(17) Rea, M. S. (ed.): IESNA Lighting Handbook: Reference and Application, 9th ed., New York, NY, Illuminating Engineering Society of North America (2000).

(18) Narendran, N., Vasconez, S., Boyce, P. R. and Eklund, H. N.: Just perceivable color differences between similar light sources in display lighting applications, J. Illum. Engng. Soc., Vol.29 No.2, pp.6877 (2000). 